\title{
Study of Histomorphological Spectrum of Benign Breast Diseases in a Tertiary Care Centre of Mumbai
}

\author{
Darshana Narayan Wakkar'1, Prashant Shrimant Dorkar² \\ ${ }^{1}$ Department of Pathology, BVDU College and Hospital, Sangli, Maharashtra, India. \\ ${ }^{2}$ Department of General Surgery, Government Medical College \& Hospital, Miraj, Maharashtra, India.
}

\section{ABSTRACT}

\section{BACKGROUND}

Breast, a modified sweat gland exhibits a wide spectrum of pathological lesions, usually presenting as palpable masses ranging from inflammatory to neoplastic lesions. Neoplastic lesions can be either benign or malignant. These lumps are always a cause of anxiety to the patients and their family members. ${ }^{1}$ Breast diseases are showing a rising trend worldwide. A number of studies have been done in order to know the magnitude of the problem. The present study was undertaken with an aim to determine the incidence and the histopathological spectrum of various benign breast lesions at our institute.

\section{METHODS}

The present study of the breast lesions was performed in the department of pathology in a general teaching hospital and tertiary referral health care centre in Mumbai. The information and data from clinical records was collected and analysed.

\section{RESULTS}

A total of 953 cases of breast lesions was studied and analyzed over a period of 10 years and 10 months. Of the total 953 cases, 653 (68\%) cases were benign lesions. Fibroadenoma (63\%) was the commonest lesion followed by inflammatory lesions (12\%) and benign phyllodes tumour (5.7\%).

\section{CONCLUSIONS}

The term "benign breast diseases" encompasses a heterogeneous group of lesions that may present with a wide range of symptoms or may be detected as incidental microscopic findings, and these are more frequent lesions of breast than malignant ones. Histopathological study plays important role to reach the correct diagnosis in certain benign breast diseases which mimic cancers clinically. Present study is in concordance with other studies showing fibroadenoma as commonest benign breast lesion.

\section{KEY WORDS}

Breast Lesions, Benign, Fibroadenoma, Phyllodes Tumour
Corresponding Author: Dr. Darshana Narayan Wokkar, Pot No. 11, Shantisagar Housing Society, Bharat Nagar, Near Datt Mandir, Miraj-416410, Maharashtra, India. E-mail: darshanawokkor@gmail.com

DOI: $10.14260 /$ jemds/2020/282

Financial or Other Competing Interests: None.

How to Cite This Article: Wakkar DN, Dorkar, PS. Study of histomorphological spectrum of benign breast diseases in a tertiary care centre of Mumbai. J. Evolution Med. Dent. Sci. 2020;9(15):1300-1304, DOI: 10.14260/jemds/2020/282

Submission 07-02-2020,

Peer Review 21-03-2020,

Acceptance 27-03-2020,

Published 13-04-2020.

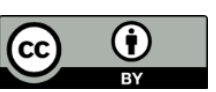




\section{BACKGROUND}

Breast, a modified sweat gland exhibits a wide spectrum of pathological lesions, usually presenting as palpable masses ranging from inflammatory to neoplastic lesions. Neoplastic lesions can be either benign or malignant type; these lumps are always a cause of anxiety to the patients and their family members. ${ }^{1}$ Most of breast lumps are benign but most of these patients are in a state of heightened anxiety until they have undergone specialist assessment, the necessary investigations with eventual reassuarance. ${ }^{2}$ Breast diseases are showing a rising trend worldwide. A number of studies have been done in order to know the magnitude of the problem. The term "benign breast diseases" encompasses a heterogeneous group of lesions that may present a wide range of symptoms or may be detected as incidental microscopic findings ${ }^{3}$ therefore histopathological examination is necessary to establish the diagnosis $^{1}$ as in some cases the clinical picture may be confusing.

The vast majority of the lesions that occur in the breast are benign. ${ }^{4}$ It is important for pathologists, radiologists, and oncologists to recognize benign lesions, both to distinguish them from in situ and invasive breast cancer and to assess a patient's risk of developing breast cancer, so that the most appropriate treatment modality for each case can be established. The present study endeavours to analyse histomorphology of various breast diseases retrospectively as well as prospectively in all age groups from the year 20022012 at a tertiary care centre. In this review, the most frequently seen benign lesions of the breast are summarized as developmental abnormalities, inflammatory lesions, benign proliferative diseases and benign neoplastic lesions.

\section{Objectives}

1. To study the frequency of breast diseases in all age groups and gender.

2. To study various types and classify them.

3. To study the clinico-pathological correlation.

\section{METHODS}

The present study of the breast lesions was performed in the department of pathology in a general teaching hospital and tertiary referral health care centre in Mumbai. The study was conducted for the period of 10 years and 9 months. It was a Descriptive study of 8 and 1/2 years (Jan 2002 to June 2010) and a descriptive study of 2 years and 3 months (July 2010 to Oct. 2012). All the Breast tissue specimens received in surgical pathology section of the Department of Pathology were included in this study. The Clinical data including age, sex, site of lesion, quadrant and size of tumour was recorded in each case. Additional information including duration of disease, any associated symptoms was recorded wherever available. Information and details from pathology records e. $g$. histomorphological types, histologic grade, lymph node status, extent of lesions and cutaneous involvement were noted.

All breast specimens received in different forms such as excisional biopsy and lumpectomy were processed by standard protocol and formalin fixed paraffin embedded tissue sections stained with haematoxylin and eosin were studied and analysed. Breast tissues were received in 10\% buffered formalin and routinely processed in Autotechnicon. Routine paraffin sections of 4- to 5-micron thickness were cut on the rotary microtome and then stained by HaematoxylinEosin stain.

\section{RESULTS}

Total 953 cases of breast lesions were studied and analysed over a period of 10 years and 9 months. The incidence of benign lesions was found to be $653(68.3 \%)$ of all the breast lesions. Out of 653 benign cases, 624 were females and 29 were males. The total number of surgical specimens was 57,500. The total number of breast lesions was 957 (1.66\%). The total number of benign breast lesions was 653 (68.3\%).

A total of 957 surgical specimens was received in the department of pathology at a tertiary hospital, Mumbai, over a period of 10 years, which formed $1.66 \%$ of the total specimens received for histopathology. There were 282 (29.46\%) mastectomy and 596 (62.27\%) lumpectomy specimens. In 79 $(8.25 \%)$ cases the specimens were labeled as breast tissues, which included core biopsies, abscess wall scrapings and paraffin block sent from outside hospital for review. Histopathological distribution of various benign lesions is shown in Table 1.

\begin{tabular}{|cccc|}
\hline Benign Lesions & Total & $\begin{array}{c}\text { (\%) of Total } \\
\text { Cases }\end{array}$ & $\begin{array}{c}\text { \% of Benign } \\
\text { Lesion }\end{array}$ \\
Fibroadenoma & 427 & 44.61 & 63.0 \\
Inflammatory Lesions & 99 & 10.34 & 12.26 \\
Phyllodes(Benign + Intermediate) & $36(24+12)$ & 3.76 & 5.73 \\
Gynecomastia & 29 & 3.03 & 4.60 \\
Fibrocystic Diseases & 24 & 2.50 & 3.80 \\
Hamartoma & 11 & 1.14 & 1.75 \\
Duct Ectasia & 10 & 1.04 & 1.59 \\
Benign Intraductal Papilloma & 07 & 0.73 & 1.11 \\
Tubular adenoma & 07 & 0.73 & 1.11 \\
Sclerosing Adenosis & 06 & 0.62 & 0.95 \\
Virginal Hypertrophy & 05 & 0.52 & 0.79 \\
Fibroadenomatoid Mastopathy & 04 & 0.41 & 0.63 \\
Galactocele & 04 & 0.41 & 0.63 \\
Fat Necrosis & 04 & 0.41 & 0.63 \\
Adenomyoepithelioma & 03 & 0.31 & 0.48 \\
Blunt Duct Adenosis & 02 & 0.20 & 0.31 \\
Benign Spindle Lesion & 01 & 0.10 & 0.15 \\
Lipoma & 01 & 0.10 & 0.15 \\
Accessary Breast & 01 & 0.10 & 0.15 \\
Columnar cell change & 01 & 0.10 & 0.15 \\
Total & $\mathbf{6 5 3}$ & $\mathbf{6 8 . 3 0}$ & $\mathbf{1 0 0}$ \\
\hline Table 1. Various Types of Benign Breast Lesions (n=653) \\
\hline \multicolumn{2}{c}{} \\
\hline
\end{tabular}

\begin{tabular}{|ccccc|}
\hline $\begin{array}{c}\text { Age } \\
\text { (Years) }\end{array}$ & Fibroadenoma & $\begin{array}{c}\text { Inflammatory } \\
\text { Lesions }\end{array}$ & $\begin{array}{c}\text { Phyllodes } \\
\text { Tumours }\end{array}$ & Gynecomastia \\
$11-20$ & 192 & 10 & 02 & 14 \\
$21-30$ & 158 & 42 & 08 & 10 \\
$31-40$ & 65 & 29 & 14 & 03 \\
$41-50$ & 12 & 16 & 09 & 01 \\
$51-60$ & 00 & 01 & 03 & 01 \\
$61-70$ & 00 & 01 & 00 & 00 \\
$71-80$ & 00 & 00 & 00 & 00 \\
Total & $\mathbf{4 2 7}$ & $\mathbf{9 9}$ & $\mathbf{3 6}$ & $\mathbf{2 9}$ \\
\hline \multicolumn{5}{c}{ Table 2. Age Distribution of Benign Diseases } \\
\hline \multicolumn{5}{|c|}{} \\
\hline
\end{tabular}

Among benign breast lesions fibroadenoma was most common comprising of $44.61 \%$ of total breast lesions and $63 \%$ of all benign diseases. It showed peak incidence within 15 to 35 years of age whereas phyllodes tumours showed peak incidence within 31 to 40 years of age. ${ }^{*}$ A single case of juvenile fibroadenoma with adenosis was seen in 16 years old 
female.*An occasional case of giant intermediate grade phyllodes with atypical ductal hyperplasia was noted in a 50 years old woman.

\begin{tabular}{|cccccc|}
\hline $\begin{array}{c}\text { Age } \\
\text { (Years) }\end{array}$ & $\begin{array}{c}\text { Fibrocystic } \\
\text { Diseases }\end{array}$ & Hamartoma & $\begin{array}{c}\text { Duct } \\
\text { Ectasia }\end{array}$ & $\begin{array}{c}\text { Benign } \\
\text { Papilloma }\end{array}$ & $\begin{array}{c}\text { Virginal } \\
\text { Hypertrophy }\end{array}$ \\
$11-20$ & 00 & 01 & 00 & 00 & 05 \\
$21-30$ & 07 & 05 & 03 & 01 & 00 \\
$31-40$ & 06 & 04 & 05 & 02 & 00 \\
$41-50$ & 07 & 00 & 01 & 01 & 00 \\
$51-60$ & 00 & 01 & 00 & 02 & 00 \\
$61-70$ & 03 & 00 & 00 & 00 & 00 \\
$71-80$ & 01 & 00 & 00 & 01 & 00 \\
Total & $\mathbf{2 4}$ & $\mathbf{1 1}$ & $\mathbf{1 0}$ & $\mathbf{0 7}$ & $\mathbf{0 5}$ \\
\hline \multicolumn{5}{c}{ Table 3. Age Distribution of Benign Diseases } \\
\hline
\end{tabular}

\section{DISCUSSION}

\section{General Considerations}

The breast or mammary gland is covered by skin and subcutaneous tissue and rests on the pectoralis muscle, from which it is separated by a fascia. The morphofunctional unit of the organ is the single gland, a complex branching structure that is topographically arranged into lobes and which is made up of two major components: the terminal duct-lobular unit (TDLU) and the large duct system. The lobule, together with its terminal duct, has been called the terminal duct lobular unit (TDLU). It connects with the subsegmental duct, which in turn leads to a segmental duct, and this to a collecting (lactiferous or galactophorous) duct, which empties into the nipple. A fusiform dilation located beneath the nipple between the collecting and the segmental duct is known as the lactiferous sinus. The acini are surrounded by loose fibrovascular intralobular stroma, which contrasts with the denser and less cellular interlobular stroma.

The TDLU is the physiologically active area of the breast and the site of origin of most pathologic lesions. The epithelium throughout the duct system is bilayered. The importance of this double cell layer is one of the main guides to the distinction between benign and malignant lesions. Breast tissue responds markedly to hormonal and other influences throughout life and as a result, it may display a wide range of normal appearances. ${ }^{11}$ Familiarity with the cyclic changes in the normal lobule is basic to the interpretation of breast histology.

For correct diagnosis of breast disease background knowledge of general features of individual breast lesions like incidence, age distribution, symptoms and palpatory findings are very important. Benign conditions of breast are significantly more common than the malignant condition in developing countries. There is limited literature available on this and it suggests that benign breast disease is a common problem in the developing countries as well. 5 The incidence of these presentations varies in different geographical areas according to the spectrum of the benign breast diseases encountered.

Pseudoangiomatous hyperplasia of stroma, Fibromatosis Neurofibroma, Leiomyoma. In our study, benign diseases are common $(68.3 \%)$ than malignant diseases $(31.7 \%)$ which is comparable to other studies. Chaudhary et al ${ }^{6}$ had carried out retrospective study of lumps in breast sent for histopathological examination in Calcutta National Medical College for a period of last 10 years and found total 2026 breast cases, out of which $74.1 \%$ were benign lesion. Whereas a Pakistani study by Siddiqui et $\mathrm{al}^{7}$ from Aga Khan University Hospital, Karachi received 3279 breast specimens over a period of 4 years showed $58.8 \%$ benign lesions In the study of Chiedozi et al, 8 total of 708 women who presented to the General Surgery Service of Prince Abdul-Rahman Al-Sudairy Central Hospital, Saudi Arabia, with breast complaints showed $91.4 \%$ of benign breast lesions and $8.6 \%$ of malignant breast lesions.

\begin{tabular}{|c|c|c|c|c|c|}
\hline 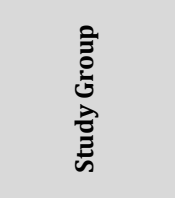 & 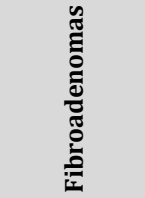 & 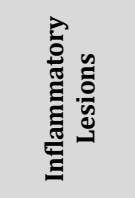 & 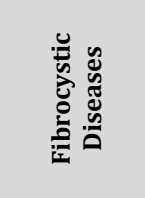 & 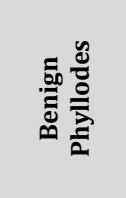 & 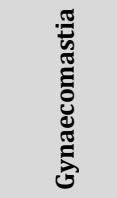 \\
\hline $\begin{array}{l}\text { Chaudhary } \\
\text { et al } 1995\end{array}$ & $950(46.07 \%)$ & $150(7.27 \%)$ & $386(18.71 \%)$ & - & $28(1.35 \%)$ \\
\hline $\begin{array}{l}\text { M. S. Siddiqui } \\
\text { et al } 1996\end{array}$ & $556(16.95 \%)$ & $461(14 \%)$ & $457(13.96 \%)$ & $19(0.57 \%)$ & - \\
\hline Singh et al 2000 & $43(28.28 \%)$ & $17(11.8 \%)$ & $33(21.71 \%)$ & - & $07(4.6 \%)$ \\
\hline $\begin{array}{c}\text { Chiedozi et al } \\
2003\end{array}$ & $138(27.5 \%)$ & $213(42.5 \%)$ & $20(2.82 \%)$ & $3(0.42 \%)$ & - \\
\hline $\begin{array}{l}\text { Rajendra K. } \\
\text { et al } 2010\end{array}$ & $53(21.8 \%)$ & $55(22.6 \%)$ & $100(41.2 \%)$ & - & $6(2.5 \%)$ \\
\hline Prajulietal 2011 & $45(39.4 \%)$ & $8(7.0 \%)$ & $21(18.4 \%)$ & - & $7(6.1 \%)$ \\
\hline $\begin{array}{l}\text { Nasser Ahmed S. } \\
\quad \text { et al } 2012\end{array}$ & $878(32.6 \%)$ & $507(18.8 \%)$ & $278(10.3 \%)$ & $43(1.6 \%)$ & - \\
\hline $\begin{array}{c}\text { Present Study } \\
2012\end{array}$ & $427(44.7 \%)$ & $99(10.3 \%)$ & $24(2.5 \%)$ & $36(3.7 \%)$ & $29(3.0 \%)$ \\
\hline
\end{tabular}

\section{Fibroadenoma}

It is a very common benign breast lesion typically occurring in patients between the ages of 20 and 35 years. It increases in size during pregnancy and tends to regress as the age of the patient increases. Grossly, the usual fibroadenoma is a sharply demarcated, firm mass, not more than $3 \mathrm{~cm}$ in diameter. The cut surface is solid, grayish white, and bulging, with a whorllike pattern and slit-like spaces. Necrosis is absent. Microscopically, it consists of a proliferation of epithelial and mesenchymal elements. The stroma proliferates around tubular glands (pericanalicular growth) or compressed cleftlike ducts (intracanalicular growth). Often both types of growth are seen in the same lesion. If the tumor assumes massive proportions ( $>10 \mathrm{~cm}$ ), more commonly observed in female adolescents, it is called Giant fibroadenoma.

Chaudhary et al studied 2062 breast lumps sent for histopathological examination in Calcutta National Medical College for a period of last 10 years retrospectively was found that fibroadenoma is most common benign breast lesions constituting $46.07 \%$ of all cases. In the current study, among benign breast diseases, fibroadenoma was the most common and constituting $44.6 \%$ (427) of cases among which conventional fibroadenomas accounted for 33.54\%( 321), $3.9 \%(38)$ were juvenile fibroadenomas and $3.23 \%$ were complex fibroadenomas. Siddiqui et al showed decreased incidence of fibroadenomas (17\%). His study was based on histopathological analysis and he studied 3279 cases at tertiary care hospital. Similar results were obtained by Chiedoziet al in 2003 (27.5\%), Rajendra K. et $\mathrm{al}^{9}$ in 2010 (21.8\%), and Nasser Ahmad et al ${ }^{10}$ in 2012 (32.6\%).

In all the above-mentioned series, fibroadenoma was found to be the most common benign breast disease. Thus, our study is in concordance with the studies available in the literature. Causes of this increased frequency are not clear. 
Racial predisposition could be a factor. Demographic factors might play a role, considering the large number of young females within the population of these groups.

In present study, fibroadenomas were seen in young and childbearing age group with peak incidence in 14 to 35 years age showing predominantly pericanalicular pattern. Oldest case detected was 50 years old (Hyalinised Fibroadenoma).We have got 7 cases $(0.7 \%)$ of tubular adenomas and 1 case $(0.1 \%)$ of lactating adenoma. Chiedozi et al and Siddiqui et al found 2 cases and 5 cases $(0.1 \%)$ of tubular adenomas respectively.

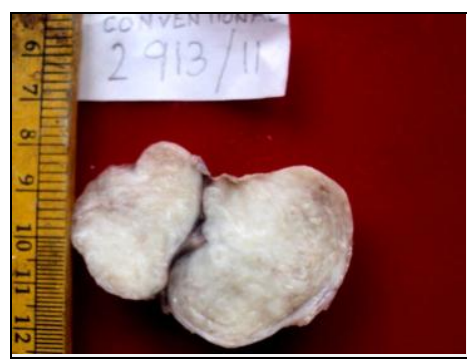

\section{Figure 1.}

Fibroadenoma-

Cut Surface Showing Homogenous Grey White with Slit like Areas

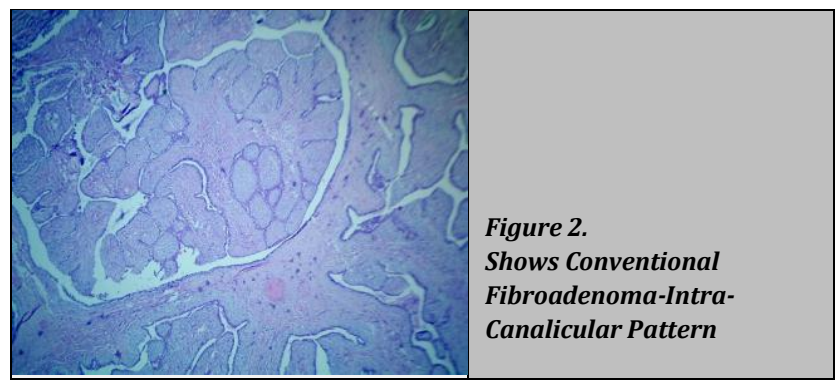

\section{Inflammatory Lesions}

The second most common benign breast disease in our study were Inflammatory lesions of the breast, accounting for $10.3 \%$ of all cases, comprising of 29 cases of acute mastitis with abscesses and 70 cases of chronic inflammation. It appears that figures for breast abscesses are underestimated because most are drained and only a minority is biopsied. In chronic inflammatory lesions, 27 were chronic mastitis, 16 were granulomatous mastitis, out of which 5 cases showed tuberculous aetiology. We also had 10 were duct ectasia and 4 cases of fat necrosis. We found 4 cases of Galactocele in young lactating females. Peak incidences of inflammatory lesions were present between age ranges of 21 to 40 years.

Chaudhary et al and Parajulis et $\mathrm{al}^{1}$ studies showed lower incidence of Inflammatory lesions i.e. 7.2\% (150 cases) and $7 \%$ (8 cases) respectively compared to present study (10.3\%). Whereas other studies, Naseer Ahmed et al(32.6\%), Rajendra et al (22.6\%), Chiedozi et al (42.5\%) and Siddiqui et $\mathrm{al}^{3}(14 \%)$ showed higher incidence of inflammatory lesions compared to present study. Benign phyllodes tumour in the present study third most common fibroepithelial lesion found was phyllodes tumour constituting 3.76\% (36 cases) of all breast lesions. This showed higher incidence compared to studies of Siddiqui et al $0.57 \%$ ( 19 cases), Chiedozi et al $0.42 \%$ ( 3 cases) and Naseer Ahmed et al 1.6\% (43 cases). In the present study, out of 36 cases, 24 were benign and 12 were intermediate grade and peak incidence is seen between age group of 31 to 40 years. 3 phyllodes tumours showed recurrences, out of which 2 were benign and 1 was of intermediate grade.

\section{Gynecomastia}

Gynecomastia is defined as the enlargement of the male breast resulting from hypertrophy and hyperplasia of both glandular and stromal components. It may result from increase in estrogenic activity (whether endogenous or exogenous), decrease in androgenic activity, or both. Gynecomastia was the commonest breast lesion in the males showing 29 cases ranking fourth most common benign breast lesion. The majority of the patients were in 11-20 years age group. Gynecomastia formed $3.03 \%$ of the all breast lesions. This incidence is higher than that seen in study of Chaudhary et al $(1.35 \%)$ and Rajendra K. et al $(2.5 \%)$, whereas Parajulis et $\mathrm{al}^{1}$ showed higher incidence $(6.14 \%)$ of Gynecomastia than the present study (3.03\%).

\section{Fibrocystic Diseases}

Fibrocystic changes (FCCs) constitute the most frequent benign disorder of the breast. Such changes generally affect premenopausal women between 20 and 50 years of age. The most common presenting symptoms are breast pain and tender nodularities in breasts. Hormonal imbalance, particularly oestrogen predominance over progesterone, seems to play an important role in its development. Fibrocystic diseases was next common benign breast disease accounting for $2.5 \%$ (24 cases) of all breast lesions. Chiedozi et al in his study showed similar incidence as $2.8 \%$ for fibrocystic diseases. Other studies, Naseer Ahmed et al from Jamshoro (10.3\%), Siddiqui et al from Pakistan (13.9\%) and Parajulis et $\mathrm{al}^{1}$ from Nepal (18.4\%) showed higher incidence of fibrocystic diseases compared to our study. The real incidence of fibrocystic disease is difficult to estimate, and diagnosis depends a great deal on individual clinical or pathological acumen.

\section{Benign Papillary Lesions}

In our study we had 7 cases $(0.7 \%)$ of Benign Intraductal Papillomas. Naseer Ahmed et al showed similar incidence $(0.7 \%)$ of Benign Intraductal Papillomas in his 10 years study. Siddiqui et al also noted similar incidence $(0.8 \%)$ in his study. Present study showed 5 cases of Benign Intraductal Papillomas presenting with bloody nipple discharge.

\section{Mesenchymal Tumours}

In our study mesenchymal tumours of breast comprised of $1.35 \%$ (13 cases) all breast lesions, out of which 11 were hamartoma, 1 benign spindle lesion and 1 Lipoma. Naseer Ahmed et al, Siddiqui et al and Chiedozi et al studied 11 cases, 9 cases and 1 case respectively of lipoma. We had 5 cases of Virginal hypertrophy, 3 cases of Adenomyoepithelioma and 1 case of accessory breast tissue.

\section{CONCLUSIONS}

The term "benign breast diseases" encompasses a heterogeneous group of lesions that may present with a wide range of symptoms or may be detected as incidental microscopic findings, and these are more frequent lesions of breast than malignant one. Histopathological study plays an 
important role to fetch the correct diagnosis in certain benign breast diseases which mimic cancers clinically. Present study is in concordance with other studies showing fibroadenoma as commonest benign breast lesion.

\section{REFERENCES}

[1] Parajuli S, Koirala U, Khatri R, et al. Histomorphological spectrum of breast lesions. J Nepal Health Res Counc2011;9(1):48-51.

[2] Ellman R,Angeli N, Christians A, et al. Psychiatric morbidity associated with screening for breast cancer.Br J Cancer 1989;60(5):781-4.

[3] Anderson TJ. Normal breast: myths, realities, prospects. ModPathol1998;11(2):115-9.

[4] Caleffi M, Filho DD, Borghetti K, et al. Cryoablation of benign breast tumours: evolution of technique and technology. Breast 2004;13(5):397-407.

[5] Krishnaswamy U. Profile of benign breast disease in urban India. Ind J Surg 2003;65(2):178-81.
[6] Chaudhari M, Sen S, Sengupta J. Breast lumps: a study of 10 years. Journal of the Indian Medical Association 1995;93(12):455-7.

[7] Siddiqui MS. Kayani N, Pervez S, etal. Pattern of breast diseases in Pakistani female population: a retrospective study. Paper presentation at the 3rd Annual National Symposium of the Aga Khan University Hospital, Karachi, September 21-22, 1996.

[8] Chiedozi LC, El-Hag IA, Kollur SM. Breast diseases in the Northern region of Saudi Arabia. Saudi Med J 2003;24(6):623-7.

[9] Kumar R. A clinicopathologic study of breast lumps in Bhairahwa, Nepal. Asian Pasific J Cancer Prev 2010;11(4):855-8.

[10] Shaikh NA, Ikram-Ud-Din U, Chang F, et al. Breast diseases: pattern at LUMHS, 10 years of experience of consecutive referrals to public sector medical university at Hyderabad/Jamshoro. Professional Med J 2012;19(3):356-9. 